\title{
Interpretations of CEOs’ Responsibilities During Corporate Crises in Japan
}

\author{
Keiko Katagata, Kenichi Takano \\ Keio University, Yokohama, Japan
}

\begin{abstract}
This article examines organizational crises and responses in Japan, focusing on chief executive officer (CEO) resignations to take responsibility and other punitive consequences as well as discussing the possible relationships between corporate crises and how CEOs accept their responsibilities, including resignation. A CEO’s voluntary step-down is sometimes regarded a Japanese custom. Even though CEOs are presumably the most influential members of firms, there have been few studies of this topic. Eighty-eight corporate crises that occurred in Japan over the past 10 years were examined, on the basis of which this study defines an explanation of how CEOs take responsibility using the following variables: the location of a crisis's cause (origin), the degree to which a crisis could have been prevented (controllability), degree of damage, and the degree to which the crisis response was appropriate. Theoretical analyses of actual cases suggest that, besides the direct involvement of CEOs in intentional misconduct, problematic daily performance and poor crisis response influence their resignations and other penalty types. These findings imply that the consequences of how CEOs claim responsibility can be explained by several significant factors. Generally, the results show that CEOs do not take self-punitive actions, including resignations, because of Japanese custom but because of their performances and the degrees of damage the corresponding crises caused.
\end{abstract}

Keywords: corporate crisis, crisis communication, chief executive officer (CEO) resignation, Japan

\section{Introduction}

In Japan, chief executive officers (CEOs) frequently announce their voluntary resignations or acceptances of punitive consequences for company crises regardless of whether they are directly involved in them.

Whenever CEOs resign and face punitive responses in times of crisis, the media is always interested. Almost without fail, when a corporation must face the media during crises, the media questions the event and writes about it. People in Japan pay much attention to whether CEOs stay in their positions, but few studies have focused on those CEOs' responses.

It is important to clarify why CEOs resign or accept different punitive actions when faced with a crisis, since the method of accepting responsibility is critical to recovering stakeholders' trust and minimizing the damage. This study regards CEO resignations and other voluntary punitive actions as a form of crisis response, and it aims to systematically examine the factors that affect the need for these responses.

All organizations face corporate crises, defined as any unexpected event with the potential to cause

Keiko Katagata, Ph.D., lecturer, Graduate School of System Design and Management, Keio University, Yokohama, Japan. Kenichi Takano, Ph.D., professor, Graduate School of System Design and Management, Keio University, Yokohama, Japan. 
disrepute to an organization and jeopardize its future profitability, growth, or survival (Coombs, 1998). Corporate crises include organizational misconduct, accidents, and critical situations involving natural disasters or other external factors. Recently, corporate crises, especially misconduct, have attracted increasing attention in Japan because the corporate governance code has been enforced since 2015, with additional regulations enacted since then. Failure to respond to stakeholders after a crisis can lead to a serious secondary damage. Accordingly, corporate crisis-response processes should be developed to minimize potential damage and re-establish institutional and actional legitimacy (Boyd, 2000; Hearit, 1994). The adverse consequences of corporate crisis response that have been frequently observed, such as a large-scale outbreak of food poisoning by Snow Brand in 2000 and millions of customers' data leakage by Benesse in 2014 both in Japan, reaffirm that appropriate responses are crucial to overcome a crisis.

Meanwhile, in Western countries, researchers have identified and analyzed crisis response strategies for particular crises (Allen \& Caillouet, 1994; Benoit, 1995; Coombs \& Schmidt, 2000); however, most Western strategies have not been adopted in non-Western cultures (Huang, Wu, \& Cheng, 2016; Lee, 2004).

This research investigates the causes and effects that have resulted in dispositions such as CEO resignation and salary reduction based on actual crisis cases from Japan over the last 10 years to determine the circumstances and processes involved in corporate crises and interpret their unseen causes.

\section{Literature Review and Research Questions}

When facing crises, Japanese corporate CEOs sometimes voluntarily resign or accept punitive consequences, such as reduced salaries, even when they would not violate any criminal or civil law by not accepting such measures. Besides a CEO’s taking responsibility for fraud, his or her retirement is often attributed to a vague reason, such as "because it is a custom in Japan" and "because the top employee who faced a crisis resigned in many precedents" (Nakajima, 2007). Furthermore, while a corporate crisis attracts media attention and stakeholders' criticism, how a CEO takes responsibility, mainly through his or her resignation, continues to be a media concern.

A crisis response also includes efforts to manage stakeholders' negative reactions to the crisis and companies (Coombs, 2007), and the announcement of a CEO's retirement and other punitive consequences should be regarded as a crisis response.

“Accepting responsibility is the centerpiece of apology” (Coombs \& Holladay, 2008, p.253). Yet apology has different contexts in Japan and the West (Wagatsuma \& Rosett, 1986). In Japan, the public often sees CEOs and other top management of well-known companies, especially listed companies, apologize in front of the media in response to crises disturbing and deeply troubling to the public, even if the crises' causes and the origins of responsibility are unclear.

In Japan, an apology is mostly a sign of a desire to restore and reconcile the relationship with an opponent, but it is not necessarily directly related to liability for damage, while scholars in the West acknowledge that apology as a crisis response is the most expensive response for organizations (Fuchs-Burnett, 2002; Patel \& Reinsch, 2003). These scholars clearly imply that active crisis communication strategies, such as denial, excuses, and justification, which are common in Western countries, would not be appreciated in Japan. Meanwhile, in China, with which Japan shares some cultural features, such as a collectivistic culture (Hofstede, Hofstede, \& Minkov, 2010), societies value humble approaches (Huang et al., 2016). As an example, in the case of a cultural gap, when McDonald's Japan (MDJ)'s chicken nugget crisis erupted and MDJ provided 
detailed accounts and data regarding the incidents, it was accused by the Japanese media of making excuses (Lehmberg \& Hicks, 2018). On the other hand, in the United States (U.S.), when a Japanese banker was arrested at the Daiwa Bank's New York branch in 1995, the president in Japan announced his resignation. The New York Times explained to its American audience, “Japanese executives customarily step-down as an act of contrition if their company is involved in scandals, even if they are not directly implicated” (The New York Times, October 9, 1995).

In addition, a CEO's resignation when involved in any wrongdoing could reduce his or her legal penalty and provide the possibility of averting subsequent social sanctions in Japan. According to Tanaka (2004, p. 139), "All social sanctions (that are imposed by the mass media) are not exempt from legal sanctions, but the probability of being clearly exempt is high”. Also, he mentioned (2004) that a CEO’s retirement has the effect of converging negative reports on a corporate crisis because it implies a sincere apology to stakeholders.

Kitami (2010) examined the correlation of CEO resignation incidents and stock price movements. His study analyzed the stock prices of companies involved in corporate scandals. Figure 1 indicates four types of corporate scandals; the horizontal axis explains if the scandals happen accidentally or intentionally, and the vertical axis explains if the scandals are directly related to products and services—in other words, to end-users. His study (2010) showed that the stock market positively responds when top management takes responsibility for scandals and announces resignation (categorized as "I" and "II" in Figure 1). Although he also mentioned that a CEO's resignation is usually announced with other countermeasures, it can also be said that market favorably evaluates not only CEO resignation but the total countermeasures.

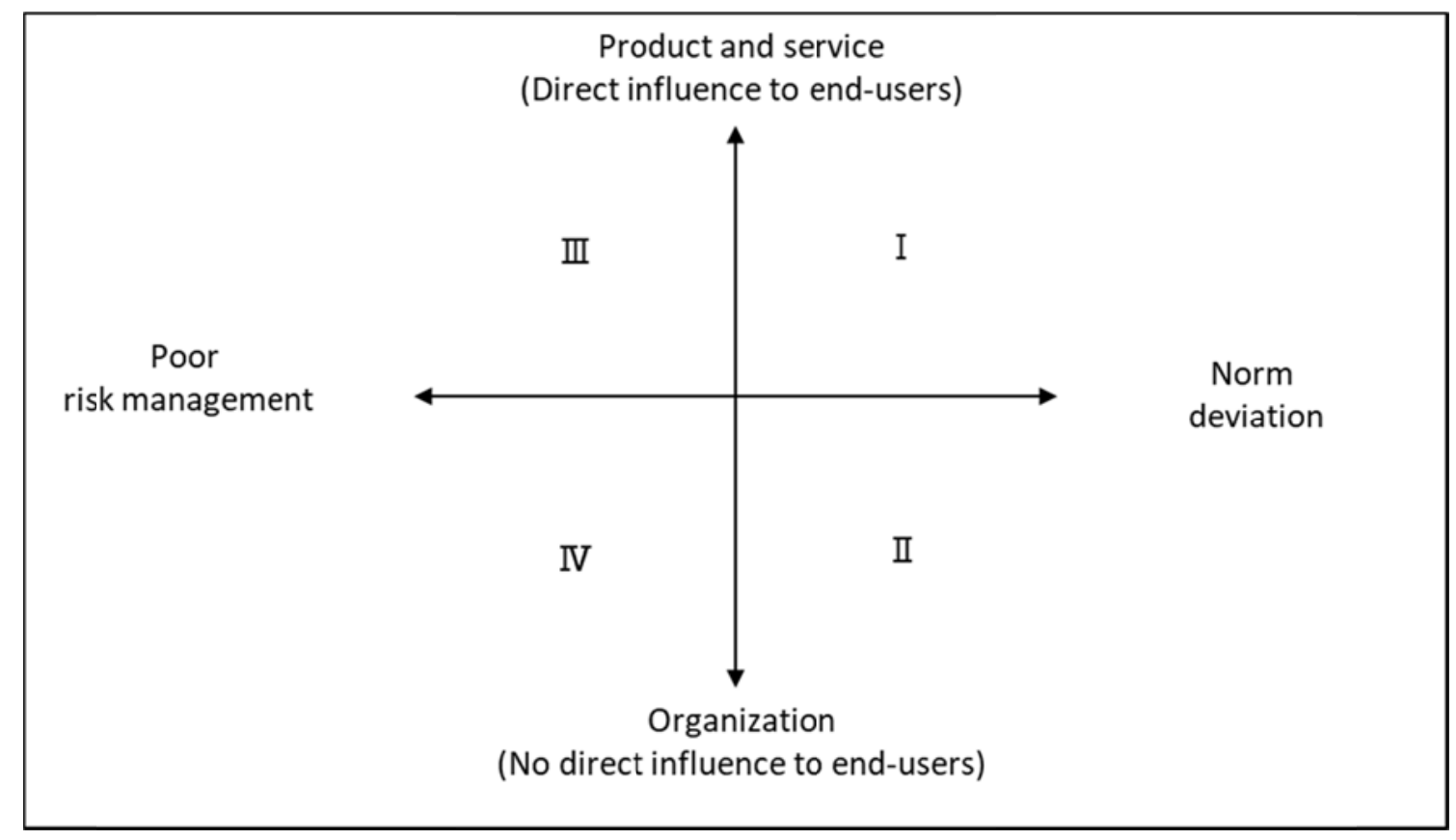

Figure 1. Corporate scandals by factor and influence. Source: Kitami (2010, p. 74).

While stakeholders in Japan sometimes witness CEOs' resignations or other punitive actions as voluntary in times of crisis, there has been no common understanding of the causal factors of these punitive actions.

RQ: What are the causal factors of CEOs' punitive actions in times of crisis? 


\section{Methodology and Results}

\section{Details of the Event Study}

Japanese cases were analyzed to derive CEOs' significantly influenceable factors regarding how they take responsibility for corporate crises. The subject of the case study was 100 crises listed in the "Corporate Scandals Index” (Takeuchi, Uetani, \& Sasamoto, 2015) edited by refereeing officially published materials, such as a legal sentence or a third-party committee investigation report. The time period covered was from March 1991 to August 2014. The analysis was conducted for 88 of the 100 cases that happened during the last 10 years, from January 2004 to August 2014.

In this research, we classified and investigated CEOs' dispositions in past corporate crises. Besides cases in which CEOs retired as a crisis response, CEOs displayed other crisis responses in that they received dispositions other than resignation, such as reductions of compensation; in some cases, CEOs did not take any disposition. Since details of CEO responses in a few cases could not be confirmed from published materials, we decided to define three simple categories: "resignation”, "other penalty”, and "no penalty” (including cases in which no penalty could be confirmed).

A survey analysis was conducted in two steps.

\section{Step 1}

Methodology. In Step 1, we clarified the crises caused by CEOs' own wrongdoings including those in which CEOs' daily management was problematic. The explanatory variables of Step 1 were the locations of crisis' causes as "origins" and the degrees to which crises could have been prevented as "controllability”, which are shown in Table 1, by referring the previous studies of Weiner (1986) and Coombs (1998).

Subsequently, Step 1 focused on the cases that were caused by a CEO's wrongdoing and examined the explanatory factors of cases in which the CEO resigned or was disposed of and applied possible factors with qualitative data. 
Table 1

Variables for Step 1

Origin Definition

(The Location of crisis 'causes)

\section{CEO}

$M$ anagem ent

Em plbyee

Extemal

\section{Controllabilify}

(The degrees to w hich crisis could have been prevented)

\begin{tabular}{|c|c|}
\hline Controllability high & Con trollability is high (intentional) \\
\hline Controllability $m$ id & Controllability is $\mathrm{m}$ iddle (preventable accident) \\
\hline Controllability low & Unintentionalnegative events \\
\hline \multicolumn{2}{|l|}{ H OW CEO recom pense } \\
\hline Resignation & ChangngCEO (IncHding resignation, dIsm ISSal) \\
\hline 0 thers & $\begin{array}{l}\text { due to corporate crisis } \\
\text { Voluntary acceptng penalty other than resignaton, }\end{array}$ \\
\hline No penaity & $\begin{array}{l}\text { such a com pensation reduction } \\
\text { No puntwe consequences }\end{array}$ \\
\hline (orno penalty confirm ed) & (orcan notbe confirm ed from published inform ation) \\
\hline
\end{tabular}

Results of Step 1. A chi-square test was conducted to investigate the relationship between 12 categories (hereafter referred to as "classifications”) and the "CEO responsibilities” of all combinations of "origin" and "controllability” of the corporate crises shown in Table 2. 
Table 2

Cross Tabulations of Origin, Controllability, and Classification

\begin{tabular}{l|rrr}
\hline \multirow{2}{*}{ Origin } & \multicolumn{3}{|c}{ CEO's Recompense } \\
\cline { 2 - 4 } & 1 Resign & 2 Other & 3 None \\
\hline CEO & 25 & 1 & 3 \\
Managements & 9 & 15 & 9 \\
Employees & 5 & 15 & 3 \\
External & 0 & 1 & 2 \\
\hline Total & 39 & 32 & 17 \\
\hline
\end{tabular}

$\left(X^{2}=38.524 a, d f=6, p<0.001\right)$

\begin{tabular}{|c|c|c|c|}
\hline \multirow[b]{2}{*}{ Controllability } & \multicolumn{3}{|c|}{ CEO's Recompense } \\
\hline & 1 Resign & 20 ther & 3 None \\
\hline High & 34 & 26 & 10 \\
\hline Mid & 5 & 6 & 5 \\
\hline Low & 0 & 0 & 2 \\
\hline Total & 39 & 32 & 17 \\
\hline
\end{tabular}

\begin{tabular}{cr|rrr}
\hline \multirow{2}{*}{ Classification } & \multicolumn{4}{|c}{ CEO's Recompense } \\
\cline { 2 - 5 } 1 & CEO\&High & 23 & 0 & 0 \\
2 & CEO\&Mid & 2 & 1 & 3 \\
3 & CEO\&Low & 0 & 0 & 0 \\
4 & Managements \&High & 7 & 11 & 5 \\
5 & Managements \&Mid & 2 & 4 & 4 \\
6 & Managements \&Low & 0 & 0 & 0 \\
7 & Employees\&High & 4 & 15 & 1 \\
8 & Employees\&Mid & 1 & 0 & 1 \\
9 & Employees\&Low & 0 & 0 & 1 \\
10 & External\&High & 0 & 0 & 0 \\
11 & External\&Mid & 0 & 1 & 0 \\
12 & External\&Low & 0 & 0 & 2 \\
\hline & Total & 39 & 32 & 17 \\
\hline$\left(\mathrm{X}^{2}=68.108^{2}, \mathrm{df}=16, \mathrm{p}<0.001\right)$ & & &
\end{tabular}

Statistical relevance remains despite an insufficient number of samples and bias toward certain variables. Consequently, the relevance of the three variables—origin, controllability, and classification—is significant for CEO responsibility $(\mathrm{p}<0.001)$. In 39 out of 88 cases, CEOs resigned. Among those 39 resignation cases, the variables explained that 23 cases were directly caused by CEOs' wrongdoing. We proceeded to hypothesize other variables that could explain the rest of cases to conduct further analysis in Step 2.

\section{Step 2}

Methodology. To examine the explanatory factors better, especially for the 16 cases in which CEOs did not directly engage in wrongdoing but resigned anyway, other factors were hypothesized. The degree of damage the crisis caused and the subsequent appropriateness of the response were both considered to affect the responsibility of the CEO.

In addition, the classification of origin and the controllability used in Step 1 were combined to correct potential bias. Like the explanatory variables of Step 2, the results of Step 1 and the variables concerning the indirect responsibility of the CEO mentioned above were reset (Table 3). 
Table 3

Variables for Step 2

\begin{tabular}{|c|c|}
\hline 0 rigin and controllability & Definition \\
\hline W rong-doing by CEO & W rong-doing by CEO \\
\hline W rong-doing by $m$ anagem ents & W rong-doing by a artoforganization including $\mathrm{m}$ anagem ents \\
\hline W rong-doing by em pbyees & W rong-doing by individuals \\
\hline Accidents and others & $\begin{array}{l}\text { Unntentonaınegatwe ncidents or ncidents } \\
\text { that are notapplicable in the above }\end{array}$ \\
\hline \multicolumn{2}{|l|}{ D egree of dam age } \\
\hline D am age inc. fatality & Crisis $w$ ith fatality \\
\hline D am age ex. fatality & $\begin{array}{l}\text { crasis w It dam ages such as neaith probem, } \\
\text { outflow of custom er inform ation, butno fatality }\end{array}$ \\
\hline No dam age & No dam age orno description of dam age \\
\hline \multicolumn{2}{|l|}{ Crisis response } \\
\hline$\overline{\text { Poor }}$ & N egative reaction caused by crisis response \\
\hline Fine & No negative reaction or no description of, caused by crisis response \\
\hline \multicolumn{2}{|l|}{ H ow CEO recom pense } \\
\hline Resignation & Changing CEO (including resignation, dism issal) due to crisis \\
\hline 0 therpenalty & $\begin{array}{l}\text { Vountary acceptng penalty other than resignation, such as } \\
\text { com pensation reduction }\end{array}$ \\
\hline $\begin{array}{l}\text { No penalty } \\
\text { (orno penalty confirm ed) }\end{array}$ & $\begin{array}{l}\text { No punitve consequences (or can not be contam ed trom pubısned } \\
\text { inform ation) }\end{array}$ \\
\hline
\end{tabular}

Table 4

Four Explanatory Variables' Combinations for Step 2 (Quantification II)

\begin{tabular}{l|c|c|c|c}
\hline \multicolumn{1}{c|}{ Total No. of Samples } & $\begin{array}{c}\text { Resignation } \\
\text { Factor analysis } \\
n=88\end{array}$ & $\begin{array}{c}\text { Other penalty } \\
\text { Factor analysis 1 } \\
n=71\end{array}$ & $\begin{array}{c}\text { Other penalty } \\
\text { Factor analysis 2 } \\
n=49\end{array}$ & $\begin{array}{c}\text { No penalty } \\
\text { Factor analysis } \\
n=88\end{array}$ \\
\hline $\begin{array}{l}\text { A. Resignation }(\mathrm{N}=39) \\
\text { B. Other penalty }(\mathrm{N}=32)\end{array}$ & $\mathrm{A}$ & $\mathrm{A}$ & excluded & $\mathrm{A}+\mathrm{B}$ \\
C. No penalty $(\mathrm{N}=17)$ & $\mathrm{B}+\mathrm{C}$ & $\mathrm{B}$ & $\mathrm{B}$ & $\mathrm{C}$ \\
\cline { 5 - 6 } & & excluded & $\mathrm{C}$ & $\mathrm{C}$ \\
\hline
\end{tabular}

To use the Quantification II method which creates the relational expression by examining the relationship between the objective variable and the explanatory variable when variables are the category data, the explanatory variable in this study needed to be adjusted in two categories, though there were three explanatory variables, Resignation, Other penalty, and No penalty. Therefore, Quantification II analysis was conducted by 
dividing the data, and calculations were carried out for the four combinations (Table 4). When analyzing the factor of other penalties, the case where the management's responsibility was classified as the CEO's resignation was the most serious consequence, and the management's responsibility classified as no penalty was the least serious. These two classified samples were then investigated separately, because it was not appropriate to combine each sample.

Results of Step 2. The results of Quantification II on the four combinations mentioned in Table 4 were shown to have several significant factors, as shown in Table 5.

In the first combination of data A versus $B+C(n=88)$, wrongdoing by CEOs and poor crisis responses were significant $(\mathrm{p}<0.001)$ with a positive coefficient.

In the second combination of data A versus B $(n=71)$, a negative coefficient of wrongdoing by CEOs and poor crisis responses compared with other penalties were shown. Damage, including fatality, had a positive coefficient, and these coefficients were significant ( $\mathrm{p}<0.05$ ); for example, when explosive fire was burned due to an unexpected error at the Mitsubishi Material Yokkaichi factory and killed five workers, the CEO announced a return of some of his remuneration.

In the third combination of data B versus C ( $\mathrm{n}=49$ ), wrongdoing by CEOs $(\mathrm{p}<0.05)$, wrongdoing by management $(\mathrm{p}<0.001)$, wrongdoing by employees $(\mathrm{p}<0.05)$, damage including fatality $(\mathrm{p}<0.05)$, and damage excluding fatality $(\mathrm{p}<0.05)$ indicated positive coefficients and were all significant.

Finally, in the combination of data A + B versus C, wrongdoing by CEOs $(\mathrm{p}<0.001)$, wrongdoing by management ( $p<0.05$ ), wrongdoing by employees $(p<0.05)$, poor crisis responses $(p<0.05)$, and damage excluding fatality $(\mathrm{p}<0.10)$ showed negative coefficients and were all significant.

Table 5

The Results of Quantification II on the Four Combinations

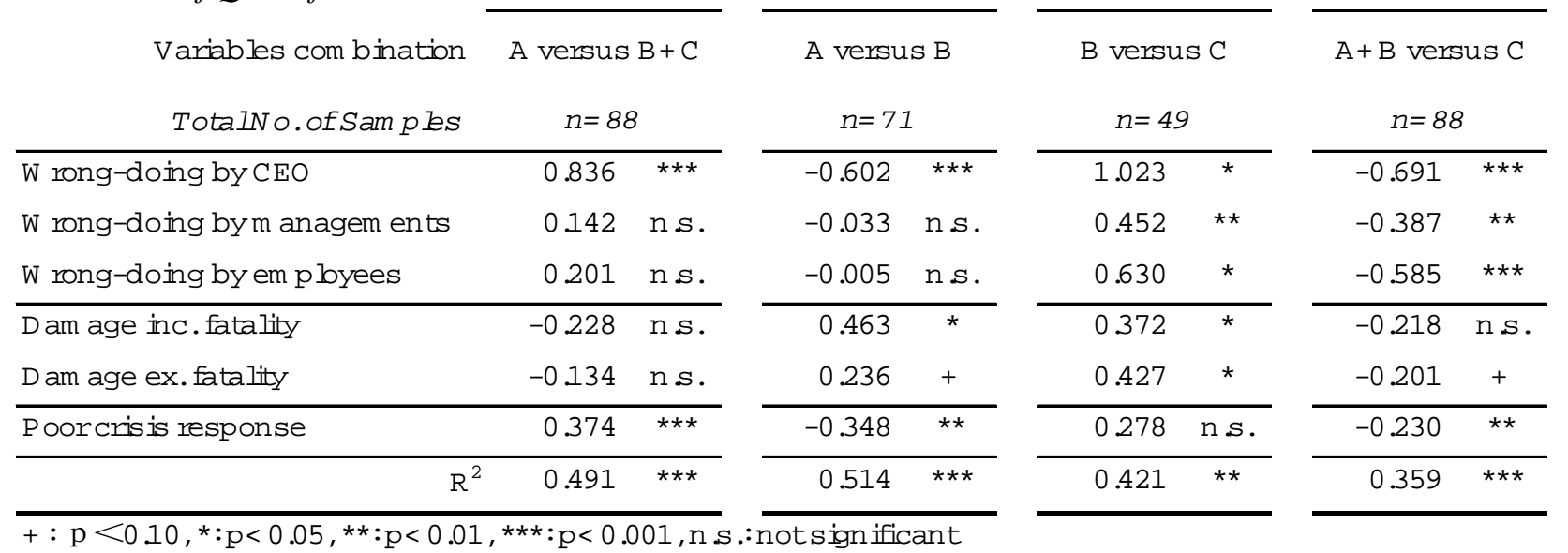

\section{Research Question}

Considering the results of Steps 1 and 2's analyses, how a CEO takes responsibility, such as resigning when faced with crises, can be explained based on the specific factors summarized in Table 6. 
Table 6

Summary of the Variables of a CEO's Response in Times of Crisis

\begin{tabular}{|c|c|c|c|}
\hline & o rigin and controllability & D egree of dam ages & Crisis response \\
\hline Resignation & W rong-doing by CEO & na. & Poor \\
\hline 0 therpenalty & $\begin{array}{l}\text { W rong-dong by } \\
m \text { anagem ents or em plbyees }\end{array}$ & $W$ ith dam ages & na. \\
\hline $\begin{array}{l}\text { No penalty } \\
\text { (orno penalty confirm ed) }\end{array}$ & Accident, or origin is extemal & & Fine \\
\hline
\end{tabular}

\section{Discussion}

The results indicate that various levels of CEO response implicitly express to stakeholders the extent to which the CEO is willing to apologize and accept punishment without words. This method of implication may relate to the Japanese tendency for collectivistic thinking (Hofstede et al., 2010) that is a value that is characterized by emphasis on cohesiveness among individuals and prioritization of the group over the self, and Japan's high-context communication culture (Hall, 1976; Meyer, 2014) which refers to the value cultures place on indirect communication.

\section{Implication of CEO Resignation}

In the survey, a total of 39 CEOs resigned in 88 crisis cases. The data show that 33 cases were because of CEO wrongdoing and that seven cases were because of poor crisis responses. Therefore, this study reveals that CEOs' own wrongdoing was the most significant factor in their resignations. CEOs' resignations to take responsibility for their misconduct are a matter of course. Also, when the original adverse events developed into more severe crises due to poor handling, such as premature media responses and inappropriate damage control, CEOs tended to announce their resignations even though the causes of the crises were out of their hands or stockholders were not forcing them out. Those poor crisis responses were mostly found in cases related to the companies' products or services that directly influenced end users rather than organizational misbehavior, such as financial frauds, insider trading, or cartels.

The implication is that stakeholders, especially consumers, think it is a CEO's role to take the lead and solve a crisis; so when they fail, stakeholders expect them to take responsibility by resigning. As Tanaka (2004) pointed out, after a CEO's announcement of resignation, it is sometimes observed that the media stops repeating negative reports, as the mass media was imposing social sanctions until accepting the CEO resignation as a sufficiently punitive consequence and an apology to society. Moreover, stakeholders in Japan might think that a crisis would influence them more than stakeholders in the U.S, since the concept of a corporation among the Japanese has pluralistic connotations, implying that the firm belongs to all the stakeholders based on a long-term relationship, while most people in the U.S. think that stockholders own companies (Yoshimori, 1995).

Furthermore, the background of CEOs' poor crisis responses can be explained by Reason's (1997) rule-related erroneous performance. He advocated three kinds of rule-related situations: good rule, bad rule, and no rule. Each type can lead to different types of erroneous performance. In the 88 samples, all the crises caused 
by employees' mistakes because no specific procedure had been provided or a rule had already been ruined induced poor crisis response from CEOs. In those cases, the chronic negligence of organizational management by CEOs was inferred. Also, these cases imply that the CEOs were indolent enough not to prepare for crises.

\section{Implications of Other Penalties}

CEOs sometimes voluntarily announce a salary cut for a certain time period instead of a resignation or take no punitive action at all in times of crisis. The results demonstrate that these events occur when management or employees, not CEOs, are involved in wrongdoing or when the crisis's damage was serious, including a fatality.

Even if a CEO does not directly cause a crisis, however, internal wrongdoings caused by management or employees tend to affect CEOs' penalties. The background of cases characteristic of this phenomenon can be explained again by Reason's (1997) rule-related erroneous performance; in these cases, management or employees obeyed harmful cultural rules. We observed the cases in which companies' excessive profit-priority cultures eventually forced them into unethical business, such as fraud. CEOs would be expected by stakeholders to manage a socially responsible company.

Moreover, stakeholders seem to think that CEOs should take responsibility when the crisis substantially damages any stakeholder whether or not the CEO is directly involved. A fatality can be important factor in a CEO's recompense, since Katagata and Takano's study (2016) also proved that the existence of a fatality influences Japanese audiences' negative emotions more severely than in the U.S.

\section{Implication of No Penalty}

A CEO's responsibility cannot be questioned even if a company's negative case is listed in the "Corporate Scandals Index” (Takeuchi et al., 2015) when the occurrence is almost impossible for the company to control, such as unexpected external factors like natural disasters, when substantial damage has not occurred, and when the company successfully performed a crisis response.

\section{Limitations}

As a limitation of this research, in the classification of controllability in Step 1, high controllability was set in cases of obvious law violation and where it was considered clearly preventable barring neglect and minimal risk management. The authors subjectively made those judgments.

\section{Conclusion}

This study statistically confirmed influential factors of how CEOs take responsibility, such as CEO resignation and salary reductions, when they face crises. Theoretical analyses of actual cases implied that, in addition to CEOs' direct involvements in intentional misconduct, other types of indirect involvement were significant factors influencing CEO resignation or taking other penalties.

These findings suggest that CEOs do not resign or take other penalties because of custom but because they are not competent leaders of organizations or because their companies caused fatal accidents. These factors broaden our understanding of the meaning of how a CEO takes responsibility in times of crisis; however, to better suggest the ideal CEO response and its effects and to explain the relationships between corporate crises and how CEOs should recompense, further investigation of additional factors is necessary, including company characteristics, such as the size and industries, and the circumstances under which CEOs announce their responsibilities. 
In addition, as indicated by preceding research, CEO acceptance of punitive action could mitigate further social sanctions and legal liability.

However, it is conceivable that real-world cases would have included CEOs' recompense with which society generally does not agree. This research subject is open for clarification regarding what severity of responsibility society demands from CEOs when their organizations face crises and the specific effect of fulfilling CEO punitive action.

\section{References}

Allen, M. W., \& Caillouet, R. H. (1994). Legitimate endeavors: Impression management strategies used by an organization in crisis. Communication Monographs, 61, 44-62.

Benoit, W. L. (1995). Accounts, excuses, and apologies: A theory of image restoration. Albany: State University of New York Press.

Boyd, J. (2000). Actional legitimation: No crisis necessary. Journal of Public Relations Research, 12, 341-353.

Coombs, W. T. (1998). An analytic framework for crisis situations: Better responses from a better understanding of the situation. Journal of Public Relations Research, 10(3), 177-191.

Coombs, W. T. (2007). Protecting organization reputations during a crisis: The development and application of situational crisis communication theory. Corporate Reputation Review, 10(3), 163-176.

Coombs, W. T., \& Holladay, S. J. (2008). Comparing apology to equivalent crisis response strategies: Clarifying apology's role and value in crisis communication. Public Relations Review, 34(3), 252-257.

Coombs, T., \& Schmidt, L. (2000). An empirical analysis of image restoration: Texaco's racism crisis. Journal of Public Relations Research, 12(2), 163-178.

Fuchs-Burnett, T. (2002). Mass public corporate apology. Dispute Resolution Journal, 57(2), 27-32.

Hall, E. T. (1976). Beyond culture. New York: Anchor Books.

Hearit, K. M. (1994). Apologies and public relations crises at Chrysler, Toshiba, and Volvo. Public Relations Review, 20, 113-125.

Hofstede, G., Hofstede, G. J., \& Minkov, M. (2010). Cultures and organizations: Software of the mind (3rd ed.). New York: McGraw Hill.

Huang, Y. H. C., Wu, F., \& Cheng, Y. (2016). Crisis communication in context: Cultural and political influences underpinning Chinese public relations practice. Public Relations Review, 42(1), 201-213.

Katagata, K., \& Takano, K. (2016). The study of crisis communication strategies in the U.S. for Japanese enterprises. Journal of the Japan Society for Management Information, 25(2), 77-95.

Kitami, K. (2010). Kigyo shakai kankei shihon to shijo hyoka: Fushoji kigyo bunseki apurochi [The corporate social capital and market valuation: Approach by analysis of corporate misdoing]. Tokyo: Gakubunsha.

Lee, B. K. (2004). Audience-oriented approach to crisis communication: A study of Hong Kong consumers' evaluation of an organizational crisis. Communication Research, 33(5), 600-618.

Lehmberg, D., \& Hicks, J. (2018). A "glocalization” approach to the internationalizing of crisis communication. Business Horizons, 61(3), 357-366.

Meyer, E. (2014). The culture map: Breaking through the invisible boundaries. New York: Public Affairs.

Nakajima, S. (2007). Sono kishakaiken machigattemasu [The press conference is wrong]. Tokyo: Nihon Keizai Shimbunsha.

Patel, A., \& Reinsch, L. (2003). Companies can apologize: Corporate apologies and legal liability. Business Communication Quarterly, 66(1), 9-25.

Reason, J. T. (1997). Managing the risks of organizational accidents. Vt.: Ashgate.

The New York Times. (1995). Chairman and president of Daiwa resign. Retrieved April 27, 2016 from http://www.nytimes.com/1995/10/09/business/ chairman-and-president-of-daiwa-resign.html

Takeuchi, A., Uehara, Y., \& Sasamoto, Y. (2015). Kigyo fushoji index [Corporate scandal index]. Tokyo, Shoji Homu.

Tanaka, T. (2004). Sorenara yurusu [Then I forgive you]! Tokyo: Bungeishunjyu.

Wagatsuma, H., \& Rosett, A. (1986). The implications of apology: Law and culture in Japan and the United States. Law \& Society Review, 20(4), 461-498.

Weiner, B. (1986). An attributional theory of motivation and emotion. New York: Springer-Verlag. 
Yoshimori, M. (1995). Whose company is it? The concept of the corporation in Japan and the West. Long Range Planning, 28(4), 2-44. 